\title{
Effect of Media, Light and pH on Growth and Sporulation of Colletotrichum musae Inciting Margin Leaf Blight of Banana
}

\author{
Prathibha Das*, P. G. Borkar, J. J. Kadam, Josiya Joy, B. G. Thaware and M. S. Joshi \\ Department of Plant Pathology, College of Agriculture, DBSKKV, Dapoli, Maharahtra, India \\ *Corresponding author
}

\section{A B S T R A C T}

\begin{tabular}{|l|}
\hline Key w o r d s \\
Colletotrichum \\
musae, Growth, \\
Sporulation, Media, \\
Light and pH
\end{tabular}

\section{Introduction}

Banana (Musa spp.) is a monocotyledonous perennial herb grown in tropical and subtropical countries contributing to food security, nutrition and poverty alleviation (Passos et al., 2013). It is one of the world's major staple food crops ranking eighth after maize, wheat, rice, potato, cassava, soybean and barley (FAOSTAT, 2013). In India, banana is the second most important fruit crop next to mango. It belongs to the family Musaceae and different varieties of banana are available all over the world. It is a part of the traditional heritage of India and it is a plant with multiple essential uses. Considering the various functions the plant serves, banana is referred as Kalpatharu (a plant with virtues). Apple of paradise, Adams fig and poor man's apple are other names that have given to banana. It is the cheapest fruit available with high energy and nutritious value.

Occurrence of devastating diseases and their profound impact on production is one of the most important limiting factors in banana cultivation across the world. Due to its delicate aerial and sub terrestrial plant parts, the crop succumbs to many diseases incited by fungi, bacteria and viruses. The hostpathogen interaction is governed by genetic makeup of the plant and pathogen as well. A variety resistant to a particular disease may be 
the susceptible to another pathogen. Margin leaf blight of banana caused by Colletotrichum musae is nowadays a major constraint in Konkan region and this situation is totally relatable to the above mentioned fact regarding the specificity of resistance because, Grand Naine variety grown in Konkan region was introduced as a resistant cultivar to banana bunchy top virus but under present situation, it seems to be susceptible to C.musae causing margin leaf blight. In last 23 years, the incidence of margin leaf blight disease in this variety has suddenly increased.

The initial symptoms are characterized by the appearance of light to dark brown irregular spots with grey to off-white centres which were usually surrounded by chlorotic halos specifically the margins of the adaxial leaf surface of the mature leaves. These spots later coalesced to form large patches resulting in leaf blight. The blighted region was separated from the healthy green tissue by a characteristic yellow irregular boarder.

The blighting followed by necrosis gradually extended from the leaf margin towards the midrib and finally invaded the petiole. Grey to white necrotic regions developed in the blighted area. Extensive shredding of leaves was also observed along the veins of the affected leaves. Completely damaged leaves began to hang down from the plant. This gave a flag-like appearance to the leaves. Old leaves were found to be more susceptible to the infection than the younger leaves.

Margin leaf blight disease of banana caused by C.musae is an emerging threat to banana cultivation in Konkan region. The present study was proposed to compare the growth and sporulation of $C$. musae on ten media as well as under different light regimes and $\mathrm{pH}$.

\section{Materials and Methods}

\section{Fungal culture}

C.musae isolated on PDA medium from leaf samples showing typical margin leaf blight symptoms was incubated at $26 \pm 2^{0} \mathrm{C}$. The cultures obtained were maintained for further studies.

\section{Culture media}

Ten different media viz., potato dextrose agar (PDA), V8 juice agar, Sabouraud's agar, Richard's agar, Czapek's dox agar, oat meal agar (OMA), water agar, Asthana and Hawker's agar, host leaf extract agar and PDA fortified with host leaf extract agar were selected to study the cultural characteristics of the pathogen. All the media were prepared as per the standard composition. The inoculated culture plates were incubated at $26 \pm 2^{0} \mathrm{C}$ by maintaining three replications for each treatment.

Observations on colony diameter were recorded after seven days of inoculation. The data on radial growth of mycelium were analyzed statistically in completely randomized design.

The number of spores per microscopic filed was counted to check the spore production in each medium. Intensity of sporulation was measured using the below mentioned scale (Unnithan, 2014).

\begin{tabular}{|l|l|l|}
\hline+ & $:$ & $\mathbf{1 - 2 5}$ conidia per microscopic field \\
\hline++ & $:$ & $26-50$ conidia per microscopic field \\
\hline+++ & $:$ & $51-75$ conidia per microscopic field \\
\hline++++ & $:$ & $>75$ conidia per microscopic field \\
\hline
\end{tabular}

\section{Light regimes}

Effect of light on growth and sporulation of the pathogen was studied on PDA medium by exposing the pure culture to different light regimes such as continuous light, continuous darkness, alternate cycles of 12 hours light and 12 hours darkness and normal room conditions. 
After inoculation the plates were incubated under different light conditions and each treatment was replicated five times in completely randomized design. Observations on colony diameter and sporulation were recorded on seventh day after inoculation and analyzed statistically.

\section{pH regimes}

To know the effect of $\mathrm{pH}$ on growth and sporulation of the isolated organism, PDA medium with different $\mathrm{pH}$ levels viz., 4.5, 5.0, 5.5, 6.0, 6.5, 7.0, 7.5 and 8.0 were used. PDA medium was prepared and $100 \mathrm{ml}$ quantity was dispensed in separate conical flasks. Different $\mathrm{pH}$ levels were adjusted by using either $0.1 \mathrm{~N} \mathrm{NaOH}$ or $0.1 \mathrm{~N} \mathrm{HCl}$ in order to obtain the desired $\mathrm{pH}$ values which were ascertained with the help of $\mathrm{pH}$ meter. The experiment was laid in completely randomized design and three replications were maintained per treatment. Observations on growth and sporulation were recorded and the data were statistically analyzed.

\section{Statistical analysis}

The data recorded in all the experiments were analyzed statistically as suggested by Gomez and Gomez (1984).

\section{Results and Discussion}

\section{Effect of culture media}

It is revealed from the data presented in Table 1 that, the colony diameter of the pathogen on three media viz., PDA $\left(\mathrm{T}_{1}\right)$, OMA $\left(\mathrm{T}_{6}\right)$ and PDA fortified with host leaf extract $\left(\mathrm{T}_{10}\right)$ was statistically at par and significantly superior to rest of the media. The maximum colony diameter $(90 \mathrm{~mm})$ was observed on these media after seven days of inoculation followed by V8 juice agar $(86.33 \mathrm{~mm})$, Richard's agar $(84.33 \mathrm{~mm})$, host leaf extract agar $(82.00 \mathrm{~mm})$, Sabouraud's agar $(80.00$ $\mathrm{mm})$ Asthana and Hawker's agar (70.00 mm) and Czapek's dox agar $(24.67 \mathrm{~mm})$. Least colony diameter $(15.33 \mathrm{~mm})$ was recorded on water agar.This indicates that all the other media except these two are suitable for culturing $C$. musae.

Excellent sporulation was observed in all the media except the host leaf extract and water agar, in which the sporulation was good and moderate respectively.

\section{Effect of light regimes on growth and sporulation}

In order to know the effect of light on the growth and sporulation of $C$. musae, the culture plates of the fungus were exposed to different light regimes such as continuous light $\left(\mathrm{T}_{1}\right)$, continuous darkness $\left(\mathrm{T}_{2}\right)$, alternate cycles of 12 hours light and 12 hours darkness $\left(\mathrm{T}_{3}\right)$ and normal room conditions $\left(\mathrm{T}_{4}\right)$ for seven days. It is clear from data presented in Table 2 that, $\mathrm{T}_{3}, \mathrm{~T}_{1}$ and $\mathrm{T}_{4}$ were significantly superior to $\mathrm{T}_{2}$ and $\mathrm{T}_{3}$ was statistically at par with $\mathrm{T}_{1}$.

Maximum sporulation was recorded when culture was exposed to alternate cycles of 12 hours light and 12 hours darkness, continuous light and under normal conditions. Sporulation was good in continuous darkness.

\section{Effect of pH on growth and sporulation}

C. musae was inoculated in culture plates with PDA medium having different $\mathrm{pH}$ levels such as $\mathrm{T}_{1}-4.5, \mathrm{~T}_{2}-5.0, \mathrm{~T}_{3}-5.5, \mathrm{~T}_{4}-6.0, \mathrm{~T}_{5}-6.5$, $\mathrm{T}_{6}-7.0, \mathrm{~T}_{7}-7.5$ and $\mathrm{T}_{8}-8.0$. The variation in growth of $C$. musaeat different $\mathrm{pH}$ was found to be significant as per the details given in Table 3.

It is apparent from Table 3 that, the pathogen grew luxuriously on PDA at $\mathrm{pH} 6.5\left(\mathrm{~T}_{5}\right)$ and 
$7.0\left(\mathrm{~T}_{6}\right)$ as the mycelium attained maximum growth $(90 \mathrm{~mm})$ in both these treatments. These two treatments were numerically superior to rest of the treatments but statistically at par with $\mathrm{T}_{4}(88.67 \mathrm{~mm}) . \mathrm{T}_{4}$ was statistically at par with $\mathrm{T}_{7}(87.00 \mathrm{~mm})$. The treatment $\mathrm{T}_{7}$ was at par with $\mathrm{T}_{8}(86 \mathrm{~mm})$ while $T_{8}$ was at par with $T_{3}(85 \mathrm{~mm})$ and $T_{2}$ $(84.33 \mathrm{~mm})$.

Table.1 Effect of media on growth and sporulation of C. musae

\begin{tabular}{|c|c|c|c|}
\hline $\begin{array}{l}\text { Tr. } \\
\text { No. }\end{array}$ & Treatments & $\begin{array}{c}\text { Colony diameter* }(\mathrm{mm}) \\
7^{\text {th }} \text { day }\end{array}$ & Sporulation \\
\hline $\mathbf{T}_{1}$ & Potato dextrose agar medium & 90.00 & ++++ \\
\hline $\mathbf{T}_{2}$ & V8 juice agar medium & 86.33 & ++++ \\
\hline $\mathbf{T}_{\mathbf{3}}$ & Sabouraud's agar medium & 80.00 & ++++ \\
\hline $\mathbf{T}_{4}$ & Richard's agar medium & 84.33 & ++++ \\
\hline $\mathbf{T}_{5}$ & Czapek's dox agar medium & 24.67 & ++++ \\
\hline $\mathbf{T}_{6}$ & Oat meal agar medium & 90.00 & ++++ \\
\hline $\mathbf{T}_{7}$ & Water agar medium & 15.33 & ++ \\
\hline $\mathbf{T}_{8}$ & Asthana and Hawker's agar medium & 70.00 & ++++ \\
\hline $\mathbf{T}_{9}$ & Host leaf extract agar medium & 82.00 & +++ \\
\hline $\mathbf{T}_{10}$ & PDA fortified with host leaf extract & 90.00 & ++++ \\
\hline & S. $\operatorname{Em}( \pm)$ & 0.38 & ----- \\
\hline & C.D@1\% & 1.53 & ----- \\
\hline & C. V \% & 0.75 & ----- \\
\hline \multicolumn{4}{|c|}{ *Mean of three replications } \\
\hline+ & : $1-25$ conidia per microscopic field & & \\
\hline++ & 26-50 conidia per microscopic field & & \\
\hline+++ & 51-75 conidia per microscopic field & & \\
\hline++++ & $>75$ conidia per microscopic field & & \\
\hline
\end{tabular}

Table.2 Effect of light regimes on growth and sporulation of C. musae

\begin{tabular}{|c|c|c|c|}
\hline Tr. No. & Treatments & $\begin{array}{c}\text { Colony diameter* }(\mathrm{mm}) 7^{\text {th }} \\
\text { day }\end{array}$ & $\begin{array}{c}\text { Sporulatio } \\
\mathbf{n}\end{array}$ \\
\hline $\mathbf{T}_{1}$ & Continuous light & 89.40 & ++++ \\
\hline $\mathbf{T}_{2}$ & Continuous darkness & 81.60 & +++ \\
\hline $\mathbf{T}_{3}$ & 12 hours light and 12 hours darkness & 90.00 & ++++ \\
\hline \multirow[t]{4}{*}{$\mathbf{T}_{4}$} & Normal room conditions & 87.80 & ++++ \\
\hline & S.Em $( \pm)$ & 0.33 & ---- \\
\hline & C.D @ 1\% & 1.36 & ----- \\
\hline & C.V.\% & 0.53 & ----- \\
\hline
\end{tabular}

\footnotetext{
*Mean of five replications

$+\quad: \quad 1-25$ conidia per microscopic field

$++\quad: \quad 26-50$ conidia per microscopic field

$++\quad: \quad 51-75$ conidia per microscopic field

$+++\quad: \quad>75$ conidia per microscopic field
} 
Table.3 Effect of $\mathrm{pH}$ on growth and sporulation of C. Musae

\begin{tabular}{|c|c|c|c|}
\hline Tr. No. & Treatments & Colony diameter*(mm) $\mathbf{7}^{\text {th }}$ day & $\begin{array}{c}\text { Sporulatio } \\
\text { n }\end{array}$ \\
\hline $\mathbf{T}_{\mathbf{1}}$ & 4.5 & 81.00 & +++ \\
\hline $\mathbf{T}_{\mathbf{2}}$ & 5.0 & 84.33 & ++++ \\
\hline $\mathbf{T}_{\mathbf{3}}$ & 5.5 & 85.00 & ++++ \\
\hline $\mathbf{T}_{\mathbf{4}}$ & 6.0 & 88.67 & ++++ \\
\hline $\mathbf{T}_{\mathbf{5}}$ & 6.5 & 90.00 & ++++ \\
\hline $\mathbf{T}_{\mathbf{6}}$ & 7.0 & 90.00 & ++++ \\
\hline $\mathbf{T}_{\mathbf{7}}$ & 7.5 & 87.00 & ++++ \\
\hline $\mathbf{T}_{\mathbf{8}}$ & 8.0 & 86.00 & ++++ \\
\hline & S.Em $(\mathbf{\pm})$ & $\mathbf{0 . 4 4}$ & ---- \\
\hline & C.D @ $\mathbf{~ \% ~}$ & $\mathbf{1 . 8 2}$ & ---- \\
\hline & C.V. $\%$ & $\mathbf{0 . 7 2}$ & ---- \\
\hline
\end{tabular}

*Mean of three replications

$+\quad$ : $1-25$ conidia per microscopic field

$++\quad: \quad 26-50$ conidia per microscopic field

$++\quad: \quad 51-75$ conidia per microscopic field

$+++\quad: \quad>75$ conidia per microscopic field

Fig.1 Effect of different media on growth of C. musae

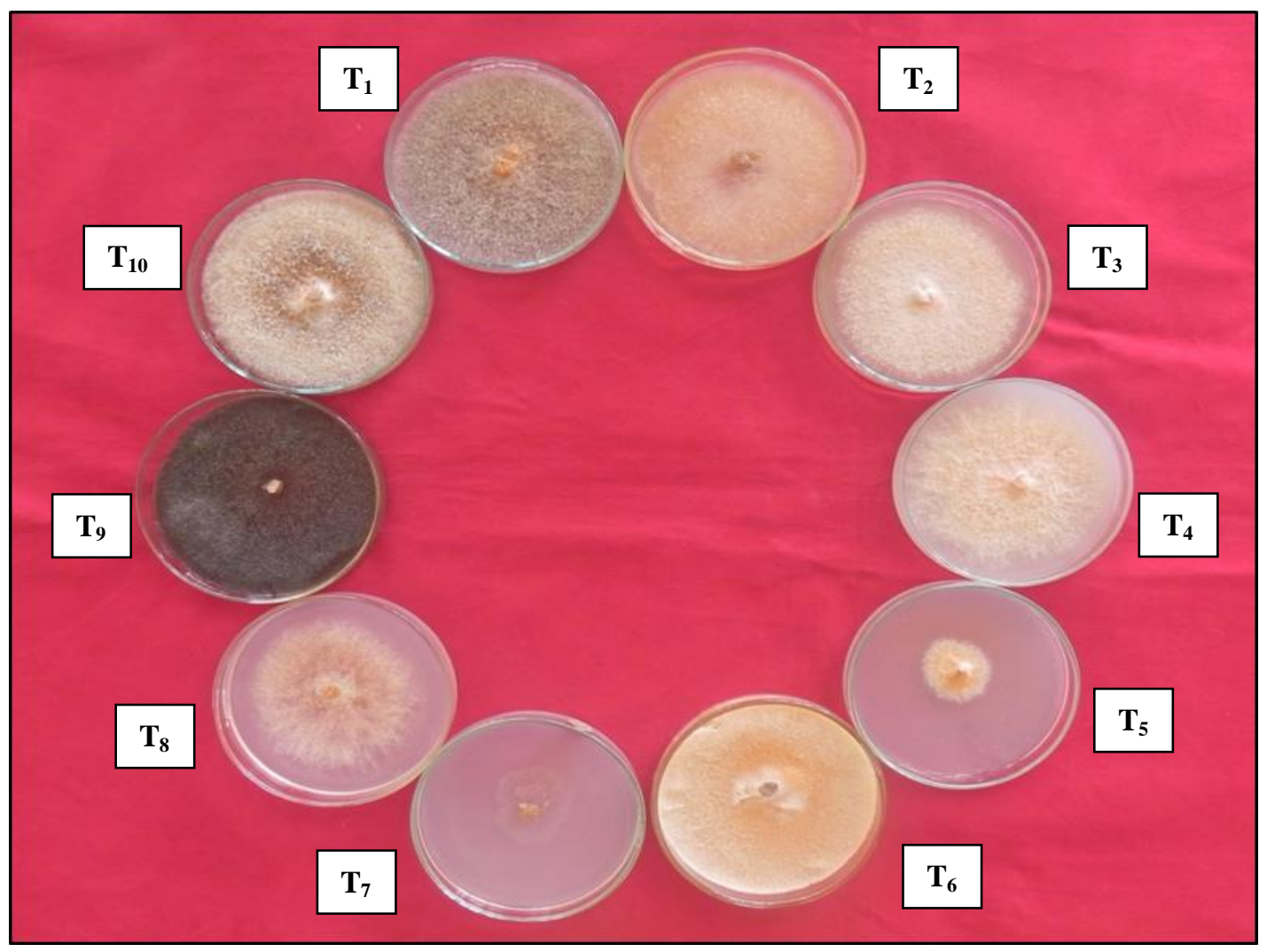


Fig.2 Effect of light regimes on growth of $C$. musae

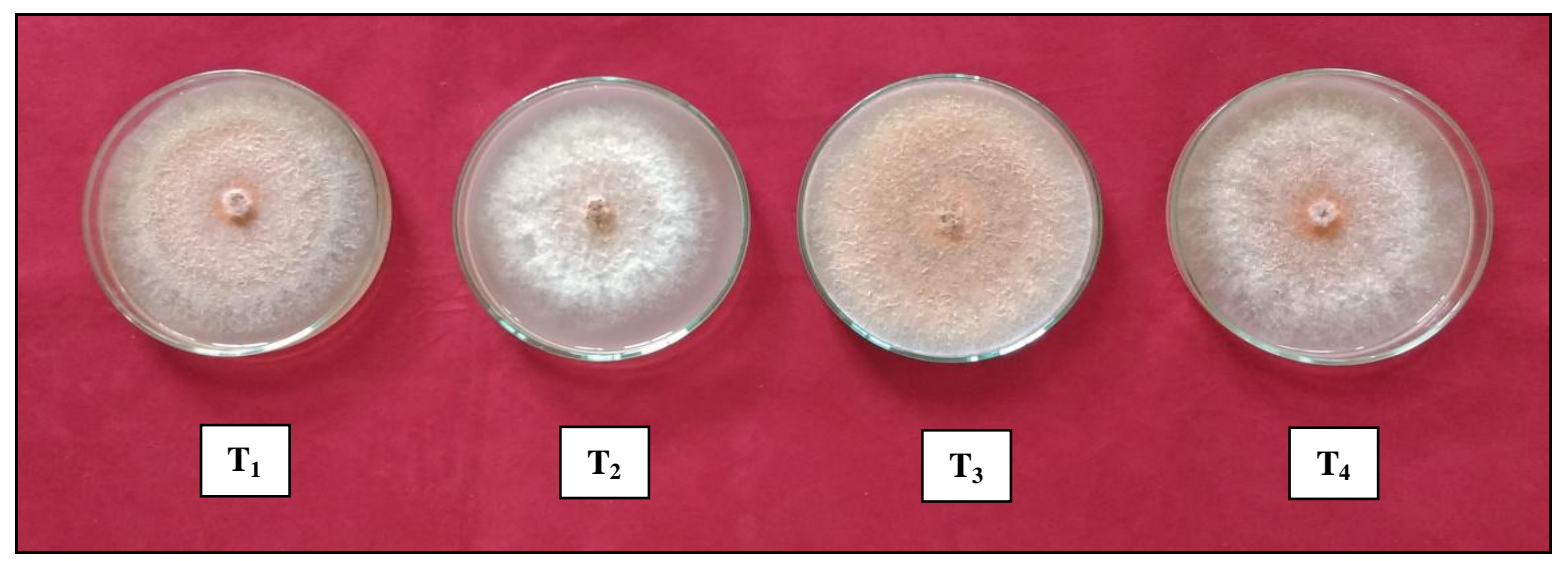

Fig.3 Effect of $\mathrm{pH}$ regimes on growth of $C$. musae

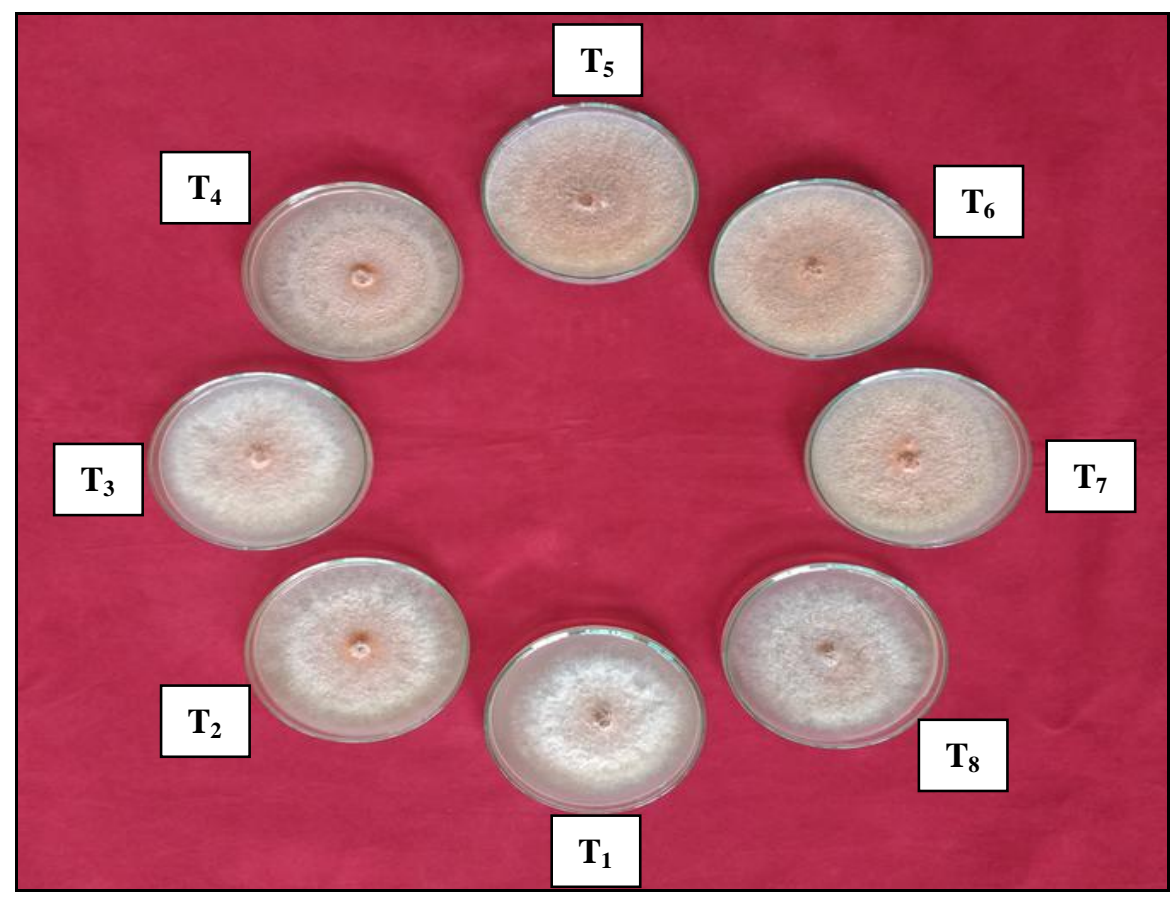

It was found from the present study that seven days of incubation under favorable conditions resulted in full growth of the isolated organismin Petri plate and hence it could be considered as the optimum growth period for further studies.

Like every other living being, proper nutrition is required for the growth and development of fungus also. Fungi derive their food from the substratum in which they are growing. Usually under laboratory conditions, fungi are grown in media supplemented with essential growth elements which can fulfill the nutrient requirement of the organism. In this study, different synthetic and non-synthetic media were used to test their influence on the growth and reproduction of $C$. musae under laboratory conditions. 
Amongst the ten media used to culture the pathogen, maximum growth and sporulation was observed on media such as potato dextrose agar (PDA), oat meal agar (OMA) and PDA fortified with host leaf extract, followed by V8 juice agar, Richard's agar, host leaf extract agar, Sabouraud's agar, Asthana and Hawker's agar and Czapek's dox agar. The least colony diameter and moderate sporulation was recorded on water agar. Thangamani et al., (2011) found that PDA medium supported abundant growth of $C$. musae while water agar was not suitable for culturing the pathogen. According to Unnithan (2014), PDA and OMA were the suitable media for culturing $C$. musae. PDA as well as carrot dextrose agar favoured maximum colony diameter of all isolates of C. musae in an experiment carried out by Priyadarshanie and Vengadaramana (2015). PDA and OMA were found to be the best media by Jaganaet al., (2017) for culturing $C$. musae.

This indicates that the composition of medium has significant effect on fungal growth as well as reproduction and medium containing higher amount of starch (PDA, OMA) supports maximum growth and sporulation of $C$. musae whereas in water agar, the mycelial growth and sporulation are adversely affected.

Ideal environs promote the optimum growth and development of microorganisms, especially when are grown under controlled conditions. Period of exposure to light and hydrogen ion concentration of the growing medium are two of the most essential factors influencing the metabolic activities of fungi and thereby creating visible changes in the physiological characteristics of the organism. The degree of influence by these two factors on the growth and sporulation varies depending on the extent of exposure in case of light and different levels in case of $\mathrm{pH}$.
Maximum growth of the $C$. musae was recorded when exposed to alternate cycles of 12 hours light and 12 hours darkness followed by continuous light and normal room conditions. Sporulation was excellent in all these three situations. The growth and sporulation was comparatively reduced when exposed to continuous darkness. This is in accordance with the findings of Thangamani et al., (2011) who reported that maximum growth of $C$. musae was obtained under alternate cycles of 12 hours darkness and 12 hours light followed by 24 hours exposure to continuous light and the least growth was recorded on exposure to 24 hours continuous darkness. An experiment conducted by Kommula et al., (2017) to understand the influence of light regimes on the growth of $C$. capsici revealed that alternate cycles of 12 hours dark and 12 hours light yielded a maximum colony growth. The findings of Unnithan et al., (2018) also pointed out that the performance of the pathogen under normal room conditions was a way better than in continuous darkness. The outcomes of present study confirmed the findings of these workers.

An optimum $\mathrm{pH}$ range for the growth and sporulation of $C$. musae was found to be 6.5 and 7.0 since the maximum colony diameter and sporulation ware obtained at these $\mathrm{pH}$ levels. These observations are in agreement with the study conducted by Thangamani et al., (2011) who mentioned that the maximum mean mycelial growth of $C$. musaeoccurred at $\mathrm{pH} 7.0$ which was at par with the mycelial growth at $\mathrm{pH}$ 6.5. Similar results were also reported by Pandey et al., (2012) in case of $C$. gloeosporioides. In an experiment conducted by De Costa and Chandima (2014), the maximum growth of $C$. musae was recorded at $\mathrm{pH}$ 4.5. These results are contradictory to the present results since the growth and sporulation of the test fungus obtained were least at this level. The dry weight of mycelial 
mat of C.musaein potato dextrose broth was maximum at $\mathrm{pH} 6.0$ and 7.0 (Jagana et al., 2017 and Unnithan et al., 2018). These findings support the results of the current study.

\section{References}

FAOSTAT, 2013.Production statistics. http://faostat.fao.org (24 March 2014).

De Costa, D. M. and Chandima, A. A. G. 2014.Effect of exogenous $\mathrm{pH}$ on development and growth of Colletotrichum musae and development of anthracnose in different banana cultivars in Sri Lanka.J. Natio. Sci. Foundation Sri Lanka. 42(3): 229-240.

Gomez, K. A. and Gomez, A. A. 1984. Statistical procedure for agricultural research. New York, Wiley, p. 78-85.

Jagana, D.,Hegde, Y. and Lella, R. 2017. Cultural and physiological characterisation of Colletotrichum musae, the causal agent of banana athracnose.Int.J. App. Biol. Pharm. Tech. 8(2): 22-30.

Kommula, S. K., Reddy, G. P. D., Undrajavarapu, P. and Kanchana, K. S. 2017. Effect of various factors (Temperature, $\mathrm{pH}$ and light intensity) on growth of Colletotrichumcapsiciisolated from infected chilli. Int. J. Pure App. Biosci.5(6): 535-543.

Pandey, A., Yadava, L. P.,Manoharan, M., Chauhan, U. K. and Pandey, B. K. 2012.Effectiveness of cultural parameters on the growth and sporulation of Colletotrichumgloeosporioides causing anthracnose disease of mango
(Mangiferaindica L.).J. Biol. Sci. 12 (4): 123-133.

Passos, M. A. N., Viviane, O. C., Flavia, L. E., Cristiane, C. T., Vânia, C. R. A., Ana, C. M. B., Edson, P. A., Claudia, F. F., Natalia, F. M., Roberto, C. T., Georgios, J. P. J., Orzenil, B. S. J. and Robert, N. G. M. 2013. Analysis of the leaf transcriptome of Musa accuminataduring interaction with Mycosphaerella musicola: gene assembly, annotation and marker development. BMC Genomics.14: 78.

Priyadarshanie, H. K. R. and Vengadaramana, A. 2015. Some preliminary studies of Colletotrichum musae associated with banana anthracnose disease in Jaffna district, Sri Lanka. Uni. J. Agrl. Res. 3(6): 197-202.

Thangamani, P. R., Kuppuswamy, P., Peeran, M. F., Gandhi, K. and Raguchander, T. 2011. Morphological and physiological characterisation of Colletotrichum musae the causal organism of banana anthracnose.W. J. Agrl. Sci. 7(6): 743754.

Unnithan, R. R. 2014. Studies on post harvest anthracnose disease of banana caused by Colletotrichum musae (Berk. \& M.A. Curtis) Arx. M. Sc. thesis, UHS, Bagalkot, Karnataka.

Unnithan, R. R., Thammaiah, N.,Kulkarni, M. S. and Gangadharappa, P. M. 2018. Physiological studies of Colletotrichum musae the causal agent of Anthracnose disease of banana. Int. J. Plant Prot.11(1): 87-92.

\section{How to cite this article:}

Prathibha Das, P. G. Borkar, J. J. Kadam, Josiya Joy, B. G. Thaware and Joshi, M. S. 2020. Effect of Media, Light and $\mathrm{pH}$ on Growth and Sporulation of Colletotrichum musae Inciting Margin Leaf Blight of Banana. Int.J.Curr.Microbiol.App.Sci. 9(07): 3538-3545. doi: https://doi.org/10.20546/ijcmas.2020.907.413 